\title{
A Study of Prevalence of Blood Group of Saudi Patients in King Abdulaziz Medical City-Riyadh
}

\author{
Mohieldin Elsayid ${ }^{1}$, Younes Yahya Aseeri ${ }^{1}$, Faisal Al Saqri ${ }^{2}$, Abdullah Alanazi $^{3}$, Shoeb Qureshi $^{4,}$ * \\ ${ }^{1}$ Department of Clinical Laboratory Sciences, College of Applied Medical Sciences, King Saud Bin Abdulaziz University for Health Sciences, \\ Riyadh, Saudi Arabia \\ ${ }^{2}$ Blood Bank Centre, King Abdul Aziz Medical City, National Guards Health Affairs, Riyadh, Saudi Arabia \\ ${ }^{3}$ Department of Emergency Medical Services, College of Applied Medical Sciences, King Saud Bin Abdulaziz University for Health \\ Sciences, Riyadh, Saudi Arabia \\ ${ }^{4}$ Research Methodology Unit, College of Applied Medical Sciences, King Saud bin Abdulaziz University for Health Sciences, Riyadh, Saudi \\ Arabia
}

\section{Email address: \\ qsab2002@yahoo.co.in (S. Qureshi)}

\section{To cite this article:}

Mohieldin Elsayid, Younes Yahya Aseeri, Faisal Al Saqri, Abdullah Alanazi, Shoeb Qureshi. A Study of Prevalence of Blood Group of Saudi Patients in King Abdulaziz Medical City-Riyadh. Science Journal of Public Health. Vol. 3, No. 4, 2015, pp. 559-562.

doi: $10.11648 /$ j.sjph.20150304.25

\begin{abstract}
Background: Blood groups have been the subject of research because of the importance of blood transfusion in surgery as well as treatment of anemia and other hemorrhagic conditions. Blood groups and immune hematological problems of blood transfusion constitute an extremely interesting, but complex study area and their investigations have much to offer to hematology and immunohematology fields. Aim: The aim of our study is to provide essential data about the distribution of $\mathrm{ABO}$ and Rhesus blood groups among Saudi populations and to determine the ABO and Rh phenotype among patients who received blood or blood products in King Abdulaziz Medical City-Riyadh. Methods: For this purpose, we retrospectively evaluated the results of ABO grouping and Rh grouping performed among some patients who received blood or blood products at King Abdulaziz Medical City Riyadh during the year 2013. Results: Participants in this study included four hundred patients (100 children; 28 youths, 88 adults and 184 olds). The gender distribution showed 232 males and 168 females. ABO phenotypes result showed that blood group $\mathrm{A}$ is $27 \%$, group B $22 \%$, group AB $3 \%$, and group $\mathrm{O}$ is $48 \%$. The percentages of positive and negative $\mathrm{Rh}$ grouping phenotypes were $96 \%$ and $4 \%$, respectively. Conclusion: In conclusion, our study shows that the blood group $\mathrm{O}$ is highly frequent among Saudi population, while the blood group AB is the lowest. Rh-negative phenotypes were not as frequent as Rh-positive.
\end{abstract}

Keywords: ABO Phenotypes, Rh Phenotypes, ABO Blood Group, ABO Antigens, Rh Antigens

\section{Introduction}

The ABO group antigens and Rhesus (Rh) blood group antigens are very useful in population genetic studies. Researching population migration patterns, as well as resolving certain clinical issues, are very important in cross matching testing at blood banking, there are many other blood group antigens, but the $\mathrm{ABO}$ blood group antigens are considered the most important in blood transfusion centers. The information about distribution of $\mathrm{ABO}$ and $\mathrm{Rh}$ blood antigens is very important in management of blood bank transfusion centers and to facilitate the transfusion services. ${ }^{[1]}$

The ABO blood antigens mainly consist of four types of blood groups, i.e. - A, B, AB and $\mathrm{O}$. The $\mathrm{ABO}$ blood group is determined by the presence or absence of the antigens $A$ and B. ${ }^{[2]}$ A good grouping of blood and blood components is a pre- requisite for an efficient blood transfusion service. ${ }^{[3,4]}$

Blood bank serology involves the study of antigen on the various cellular and soluble components and presence of antibody. However ABO blood group is closed to red cell antigens and their specificity to antibodies. There are many blood groups, depending on the basis of types of antigens on the red blood cells surface. ${ }^{[5]}$

The ABO blood group is important in blood transfusion medicine. Anti-A and anti-B antibodies are usually immunoglobulin M. ${ }^{[6]}$ The ABO blood group system consist of three allelic genes: $\mathrm{A}, \mathrm{B}$ and $\mathrm{O}$, the $\mathrm{A}$ and $\mathrm{B}$ genes control 
synthesis of specific enzymes which are responsible for the addition of single carbohydrate residues (N-acetyl glucosamine for group A and D galactose for group B) to a basic antigenic glycoprotein or glycol-lipid with terminal sugar L.Fucose on the red cell, which is known as the $\mathrm{H}$ substance. The $\mathrm{O}$ gene is an amorphic and does not transform the $\mathrm{H}$ substance. ${ }^{[5]}$

The ABO system antibodies anti A and anti B antibodies are type immunoglobulin $\mathrm{M}$, for $\mathrm{D}$-negative individuals which do not have any anti D IgG or IgM antibodies, because anti D antibodies are not usually produced by sensitization against environmental substances. ${ }^{[5]}$ (antibodies IgM), ABO IgM antibodies are produced in the first year of life by sensitization to environmental substances such as food, bacteria and viruses, the $\mathrm{O}$ blood group in $\mathrm{ABO}$ is often called 0 (zero or null). ${ }^{[5,6]}$

The $\mathrm{Rh}$ blood group system includes approximately more than 50 antigens on the red cell surface. The most significant antigen in the $\mathrm{Rh}$ system is $\mathrm{D}$ antigen, because it is most likely to produce an immune system response. ${ }^{[5]}$

The $\mathrm{Rh}$ blood group is important blood group after $\mathrm{ABO}$ in the blood transfusion services, and the $\mathrm{D}$ antigen is important antigen among $\mathrm{Rh}$ antigens in blood banking. ${ }^{[5,}{ }^{6]}$ The $\mathrm{D}$ antibody is produced in patient after stimulation or transfusion with D-positive red blood cells. ${ }^{[7]}$

In general blood group antigens have been the theme of research due to their importance of blood transfusion in many conditions. ${ }^{[8,9]}$ Blood group antigens issues related to blood transfusion medicine are very interesting as well as complex and their investigations have much to offer to blood banking, thus making role of workers in transfusion medicine more important in clinical medicine. ${ }^{[5,6]}$

This study was designed and carried out to provide data on the distributions of $\mathrm{ABO}$ and $\mathrm{Rh}$ blood groups antigens among Saudi patients who received blood or blood products at King Abdulaziz Medical City -Riyadh, which would assist in better planning, executing and coordinating bloodtransfusion services at the hospital as well as at a national level.

\section{Materials and Methods}

\subsection{Study Area}

The study was performed at King Abdulaziz Medical City (KAMC)-Riyadh, SaudiArabia.

\subsection{Study Subjects}

Male and female patients of all age groups who received blood or blood products were included, while patients who did not receive blood or blood products were excluded.

\subsection{Study Design}

This was retrospective chart review study conducted to determine the frequency of $\mathrm{ABO}$ and $\mathrm{Rh}$ phenotypes among patients who received blood or blood products.

\subsection{Sample Size}

A total of 400 patients, who received blood or blood products at King Abdulaziz Medical City-Riyadh during the year 2013 were included in the study.

\subsection{Sampling Technique}

The results of $\mathrm{ABO}$ and $\mathrm{Rh}$ phenotypes of each patient were collected from medical recordunit by using simple random technique.

\subsection{Data Collection Methods, Instruments Used, Measurements}

A computer printout of demographic data and discharge clinical events / outcomes collected from the records department for all episodes of hospital discharges that are coded for blood or blood products transfusion between January 2013 and December 2013.

\subsection{Data Analysis}

Study variables were directly entered into SPSS software. A backup soft copy version as well as a hard copy print was dated, saved and secured after each data entry was updated. Statistical analysis of study variables was carried out using SPSS software version 20 . ABO and Rh phenotypes were determined.

\subsection{Ethical Approval}

The study was approved by the Institutional Review Board of King Abdullah International Medical Research Center.

\section{Results}

Participants in this study included four hundred patients (184 old, 116 adults and 100 children) and the gender distribution of study participants showed 232 males and 168 females[Table 1]. Distribution of ABO phenotypes showed $\mathrm{A}(27 \%), \mathrm{B}(22 \%), \mathrm{AB}(3 \%)$ and $\mathrm{O}(48 \%)$ and the percentage of positive and negative Rh phenotypes were $96 \%$ and $4 \%$, respectively[Table 2, Figure 1 and 2].ABO phenotype results with respect to gender showed blood group $\mathrm{A}$ is similar between males and females, blood group B showed high frequency among males as compared to females, blood group $\mathrm{AB}$ appeared only among males and the blood group $\mathrm{O}$ was found to be high among males as compared to females [Table 3].

Table 1. Distribution of age and gender among study participants.

\begin{tabular}{llllll}
\hline $\begin{array}{l}\text { Age } \\
\text { group }\end{array}$ & Frequency & $\begin{array}{l}\text { Percent } \\
(\%)\end{array}$ & Gender & Frequency & $\begin{array}{l}\text { Percent } \\
(\%)\end{array}$ \\
\hline Child & 100 & 25 & Males & 232 & 58 \\
Adult & 116 & 29 & Females & 168 & 42 \\
Old & 184 & 46 & Total & 400 & 100 \\
Total & 400 & 100 & & & \\
\hline
\end{tabular}


Table 2. Distribution of $A B O$ and Rh phenotypes among Saudi patients.

\begin{tabular}{llllll}
\hline $\begin{array}{l}\text { Blood } \\
\text { group }\end{array}$ & Frequency & $\begin{array}{l}\text { Percent } \\
(\%)\end{array}$ & $\begin{array}{l}\text { Rh } \\
\text { phenotype }\end{array}$ & Frequency & $\begin{array}{l}\text { Percent } \\
\text { (\%) }\end{array}$ \\
\hline A & 108 & 27 & Rh & 384 & 96 \\
B & 88 & 22 & positive & & \\
AB & 12 & 3 & Rh & 16 & 4 \\
O & 192 & 48 & negative & & \\
Total & 400 & 100 & Total & 400 & 100 \\
\hline
\end{tabular}

Table 3. Distribution of ABO phenotypes in Saudi patients with respect to their gender.

\begin{tabular}{|c|c|c|c|c|c|}
\hline \multirow{2}{*}{\multicolumn{2}{|c|}{ Total \% }} & & \multicolumn{2}{|l|}{ Gender } & \multirow{2}{*}{$\begin{array}{l}\text { Blood } \\
\text { group }\end{array}$} \\
\hline & & & Female & Male & \\
\hline $27 \%$ & & & $13 \%$ & $14 \%$ & A \\
\hline $22 \%$ & & & $9 \%$ & $13 \%$ & B \\
\hline $3 \%$ & & & $0 \%$ & $3 \%$ & $\mathrm{AB}$ \\
\hline $48 \%$ & & & $20 \%$ & $28 \%$ & $\mathrm{O}$ \\
\hline 100 & 42 & 58 & Total & & \\
\hline
\end{tabular}

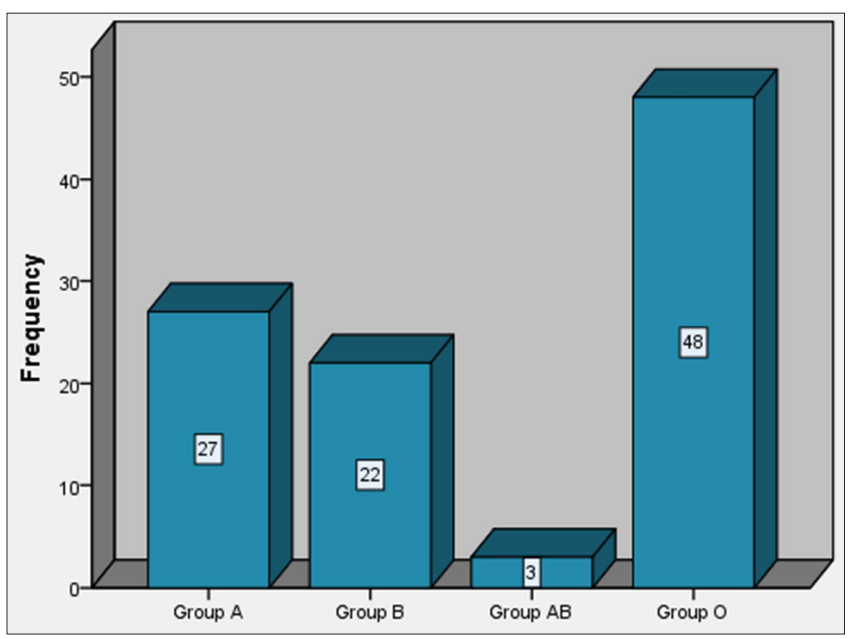

Figure 1. Frequency of ABO phenotypes among study participants.

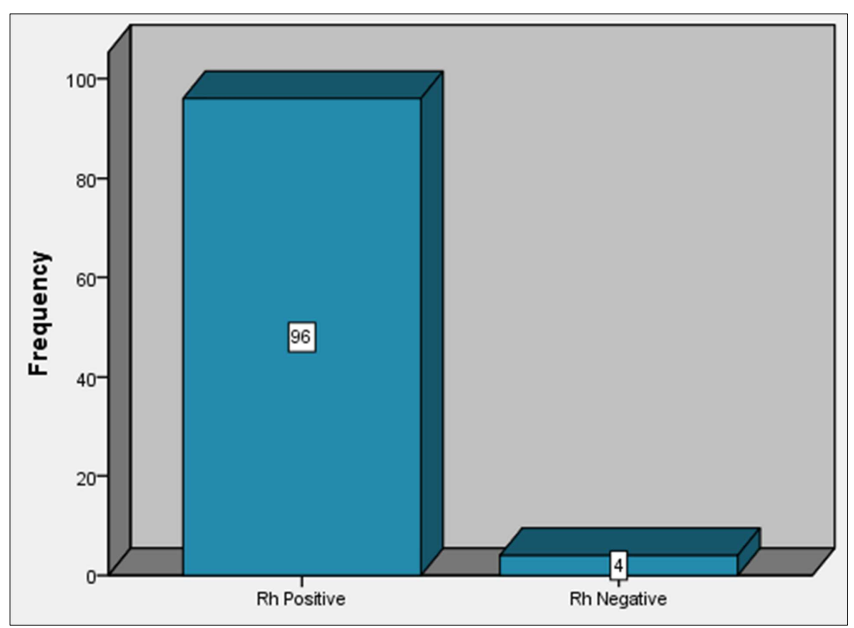

Figure 2. Percentage of Rh phenotypes among study participants.

\section{Discussion}

Literature reports suggest wide geographical and racial disparity of $\mathrm{ABO}$ and $\mathrm{Rh}$ antigens and genes. ${ }^{[9,10]} \mathrm{The}$ distribution of $\mathrm{ABO}$ and $\mathrm{Rh}$ phenotypes is universally acclaimed to play a significant role in blood transfusion compatibility between the donor and recipient, hemolytic diseases among the newborns and also in legal problems related to forensic medicine purposes. ${ }^{[9-11]}$

Data related to $\mathrm{ABO}$ blood groups revealed that frequency of: O blood group was (48\%), A blood group (27\%), B blood group (22\%), $\mathrm{AB}$ blood group (3\%) and $\mathrm{Rh}$ blood groups, frequency of $\mathrm{Rh}$ positive was (96\%), and $\mathrm{Rh}$ negative was (4\%).Therefore the most common ABO blood group among Saudi populations was found to be group O $(46 \%)$, while in major Sudanese populations frequency of blood group $\mathrm{O}$ has been reported to be (58\%), while in Western European it has been found to be $(44 \%){ }^{[3,12]}$

Blood group A phenotype was less common among Saudi populations(27\%); while among Sudanese populations, has been found to be $(40 \%) .{ }^{[13]}$ The results of present study on blood group B among Saudi population (22\%) was more than Syrian Arabs (13.13\%). ${ }^{[12]}$ It also indicates that group B in Saudi population has been shown to be of a similar frequency to Nigerian population. ${ }^{[14]}$

\section{Conclusion}

The blood group $\mathrm{O}$ is highly frequent among Saudi population, while the blood group $\mathrm{AB}$ is the lowest. The $\mathrm{Rh}$ positive phenotype is mostly frequent, while the $\mathrm{Rh}$ negative is found less frequent. The variation in frequency of blood groups and $\mathrm{Rh}$ phenotypes is due to difference in racial and geographical differences as well as migration move.

\section{Recommendations}

1. Full $\mathrm{Rh}$ phenotypes for common antigens should be performed routinely in the blood bank particularly for the pregnant women, previously transfused patients and patients with known irregular antibodies.

2. Typing of other blood groups that are very helpful for studying complicated evolutionary history should be performed routinely.

3. Study of the correlation between the blood groups and some diseases that are common in the community.

4. The $\mathrm{D}^{\mathrm{u}}$ and other Rhesus-variant that have clinical significance should be determined among individuals in the community.

5. DNA analysis should be performed to identify the actual genotypes of the individuals in the community.

\section{References}

[1] Worlledge S, Ogiemudia SE, Thomas CO, Ikoku BN, Luzzatto L. Blood group antigens and antibodies in Nigeria. Ann Trop Med Parasitol. 1974 Sep; 68(3):249-64.

[2] Jeremiah, Z.A \&Buseri, F.I. (2003). Rh antigen and phenotype frequencies and probable genotypes for the four main ethnic groups in Port Harcourt, Nigeria. Immunohematology, 19(3):86-88. 
[3] Mollison, P. L., Engelfriet, C. P. \&Marcelac. (1997). Blood transfusion in clinical medicine. ${ }^{10}$ th edition, Oxford Blackwell scientific publications.

[4] Mouro, I., Colin, Y., Chérif-Zahar, B., Cartron, J. P. \& Le Van Kim C. (1993). Molecular genetic basis of the human Rhesus blood group system. Nature Genet, 5:62-65.

[5] Hoffbrand A.V and Pettit. A.E,(2001). Post graduates hematology, $4^{\text {th }}$ edition British library, London.

[6] Genetic. In:laird fryer b Daniels G Levitt's (eds) , (1990) Blood group system kell, Arlington VA American association of blood banks.

[7] Kamla-Raj (,2009), Anthropologist, 11(3): 237-238 (2009), K. S. N. Reddy and G. Sudha, Department of Anthropology, Sri Venkateswara University, Tirupati 517 502, Andhra Pradesh, India.

[8] Sri Venkateswara University, Tirupati 517 502, Andhra Pradesh, India.

[9] Brown, T. A. (1992). Genetics: A Molecular Approach. Singapore: Fong \& sons printers; pp: 309-327.
[10] Dacie JV, Lewis SM. Practical hematology. In: Lewis SM, Bain BJ, Bates I, editors. 9th ed. London: Churchill Livingstone, Harcourt Publishers Limited; 2001. pp. 444-51.

[11] Vengelen-Tyler, editor. Technical manual. $12^{\text {th }}$ ed. Bethesda MD: American Association of Blood Banks; 1996.

[12] Polesky HF. Blood group, human leukocytes antigens and DNA polymorphism in parenting testing. In: Henry JB, editor. Clinical diagnosis and management by laboratory methods. 19th ed. Philadelphelphia: WB Saunders; 1996. pp. 1413-26.

[13] Sakharov RS, Nofal' KhK. The frequency of ABO blood groups and the expression of group antigens and isohemagglutinins in Syrian Arabs. Sud Med Ekspert. 1996 Apr-Jun;39(2):34-6.

[14] Abu-Sin AY, Ayoub M, Abdelrazig H. Antenatal blood group serology in Sudanese women. Vox Sang. 1978; 34(6):347-50.

[15] Egesie UG1, Egesie OJ, Usar I, Johnbull TO. Distribution of $\mathrm{ABO}$, Rhesus blood and haemoglobin electrophoresis among the undergraduate students of Niger Delta State University, Nigeria. Niger J Physiol Sci. 2008 Jun-Dec; 23(1-2):5-8. 